\title{
Preparation and Evaluation of PEGylated Poly-L-ornithine Complex as a Novel Absorption Enhancer
}

\author{
Yusuke Kamiya, ${ }^{a}$ Tsutomu Yamaki, ${ }^{a}$ Masaki Uchida, ${ }^{a}$ Tomomi Hatanaka, ${ }^{b}$ Mitsutoshi Kimura, ${ }^{a}$ \\ Masahiko Ogihara, ${ }^{a}$ Yasunori Morimoto,${ }^{a}$ and Hideshi Natsume*,a \\ ${ }^{a}$ Faculty of Pharmaceutical Sciences, Josai University; 1-1 Keyakidai, Sakado, Saitama 350-0295, Japan: and \\ ${ }^{b}$ Tokai University School of Medicine; 143 Shimokasuya, Isehara, Kanagawa 259-1193, Japan. \\ Received September 30, 2016; accepted November 23, 2016
}

\begin{abstract}
Polycationic compounds, such as poly-L-arginine and poly-L-ornithine (PLO), enhance the nasal absorption of hydrophilic macromolecular drugs. However, the bio availability corresponding to the dose of these enhancers has not been obtained in an open system study, where an administered solution is transferred to the pharynx because they do not exhibit mucoadhesion/retention in the nasal cavity. In this study, we prepared PEGylated-poly-L-ornithine (PEG-PLO) and investigated the effects of PEGylation on in vitro adhesion/retention properties, permeation enhancement efficiency, and cytotoxicity. PEG-PLO bearing 3-4 polyethylene glycol (PEG) chains per PLO molecule was more retentive than unmodified PLO on an inclined plate. The permeability of a model drug, FD-4, across Caco-2 cell sheets was enhanced by PEG-PLO as well as by PLO. PLO showed cytotoxicity at high concentrations, whereas PEG-PLO did not decrease cell viability, even above the concentration giving a sufficient enhancement effect. These findings suggest that PEGylation of polycationic absorption enhancers improves their adhesion/retention and decreases their cytotoxicity, which may lead to enhancers with greater utility.
\end{abstract}

Key words poly-L-ornithine (PLO); polyethylene glycol (PEG); permeation enhancer

Bioactive peptides, such as insulin, teriparatide, liraglutide, and somatropin, have been used widely as therapeutic drugs because of their intrinsic and effective activities, however, they have poor permeability across the epithelium because they are hydrophilic macromolecules. Orally administered peptides are often inactivated in the gastrointestinal tract, and thus peptides are usually administered as injectable formulations. However, injection can result in poor compliance because it is painful and burdensome. ${ }^{1)}$ Therefore, alternative routes of administration are required.

The nasal mucosa has a large surface area for absorption because of its villus structure. Drugs absorbed across the nasal mucosa avoid the hepatic first pass effect because of the abundant vasculature under the nasal mucosa. ${ }^{2)}$ The intranasal route is effective for absorbing high molecular weight drugs ${ }^{3)}$ and is usually not painful. Therefore, intranasal administration is an important alternative route to injection for peptides and proteins.

Polycationic compounds, such as poly-L-arginine (PLA), poly-L-lysine, and poly-L-ornithine (PLO), enhance the transmucosal absorption of hydrophilic macromolecules. ${ }^{4,5)}$ PLA enhances the paracellular permeability of rabbit nasal mucosa and Caco-2 cell sheets reversibly. ${ }^{6,7)}$ The absorption of hydrophilic macromolecules across the nasal mucosa in rats is also increased by co-administration with PLA. ${ }^{8)}$ PLA enhances the permeability by altering the localization of tight junction proteins from the cell-cell junction to the intracellular space without causing cytotoxicity. ${ }^{9)}$ Therefore, polycationic absorption enhancers are useful in developing efficient transmucosal drug delivery systems.

Nevertheless, it is difficult to increase the bioavailability of drugs via intranasal administration by only increasing the absorption rate. There are two clearance mechanisms in the nasal cavity: mucociliary clearance by cilia and physical clear- ance via the structure of the nasal cavity. ${ }^{3,10,11)}$ The substances trapped in the nasal mucus are transferred to the pharynx by these mechanisms, and drugs and absorption enhancers administered in the nasal cavity are removed from the absorption area. Polycationic absorption enhancers do not have mucoadhesive/retentive properties. Hence, the bioavailability corresponding to the dose of these absorption enhancers has not been obtained in an open system study, where an administered solution is transferred to the pharynx. Therefore, the development of functional polycations with mucoadhesive/ retentive properties is important for the transmucosal delivery of hydrophilic macromolecules.

PLO is a homopolymer consisting of L-ornithine, which has a primary amine on its side chain and is positively charged under physiological conditions, similar to PLA. In a preliminary study, we confirmed that PLO also altered localization of tight junction proteins and enhanced the permeation of hydrophilic macromolecules (unpublished results).

We intend to develop functional polycations by chemical modification of the functional compound. It has been suggested that both the absorption enhancement and the retentivity in nasal cavity were important to improve the transnasal delivery of unabsorbable drugs ${ }^{12)}$ and PEGylation of proteins increased the viscosity of them. ${ }^{13)}$ Polyethylene glycol (PEG) is widely used as a pharmaceutical additive and in pharmaceutical modifications. ${ }^{14)}$ The chemical modification of pharmaceuticals, such as peptides, proteins, and antibodies, with PEG modifies their physiological and physicochemical properties. ${ }^{15-17)}$ Furthermore, it has been reported that hydrogel having PEG chain on its surface shows the mucoadhesive ability by interaction with mucosa. ${ }^{18)}$

In this study, we investigated the effect of PEGylating polycations on their permeation enhancement to develop superior absorption enhancers. We prepared PEGylated-PLO and deter- 


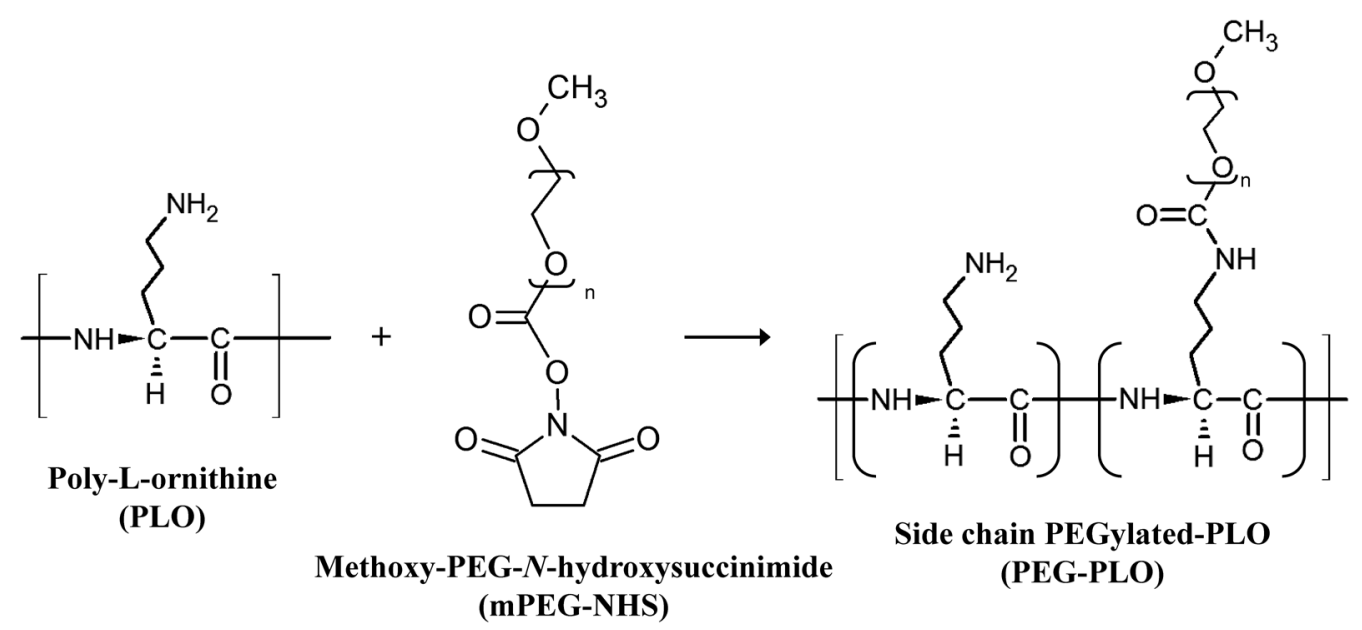

Fig. 1. Synthesis of the Side Chain PEGylated-PLO with mPEG-NHS

PLO and mPEG-NHS were mixed in a $1: 5 \mathrm{M}$ ratio. The mixture was stirred overnight at room temperature (r.t.).

mined its in vitro adhesion/retention, permeation enhancement efficiency, and cytotoxicity.

\section{MATERIALS AND METHODS}

Materials PLO hydrobromide (molecular weight (MW) $18.5 \mathrm{kDa}$ ) was purchased from Alamanda Polymers, Inc. (Huntsville, AL, U.S.A.). $\alpha$-Succinimidyloxy carbonyl- $\omega-$ methoxy polyoxyethylene (mPEG-NHS; SUNBRIGHT ME400TS, MW $40.2 \mathrm{kDa}$ ), $\alpha$-methyl- $\omega$-aminopropoxy polyoxyethylene (mPEG-NH ${ }_{2}$; SUNBRIGHT MEPA-40T, MW $42.5 \mathrm{kDa}$ ), and $\alpha$-mercaptoethyl- $\omega$-methoxy polyoxyethylene (mPEG-SH; SUNBRIGHT ME-400SH; MW 39.4kDa) were obtained from NOF Corporation (Tokyo, Japan). Fluorescein isothiocyanate dextran (FD-4, MW 3.7 kDa) was purchased from Sigma-Aldrich (St. Louis, MO, U.S.A.). 2-Morpholinoethanesulfonic acid monohydrate (MES) and 3-(4,5-dimethyl-2-thiazolyl)-2,5-diphenyl-2H-tetrazolium bromide (MTT) were obtained from Dojindo Laboratories (Kumamoto, Japan). The cell culture reagents and supplies were purchased from Thermo Fisher Scientific, Inc. (Waltham, MA, U.S.A.). 2,4,6-Trinitrobenzenesulfonic acid (TNBS) was obtained from Wako Pure Chemical Industries, Ltd. (Osaka, Japan). All other reagents were of analytical grade.

Cell Culture Human colorectal adenocarcinoma Caco-2 cells were purchased from the American Type Culture Collection (Manassas, VA, U.S.A.) and used for all cell culture experiments. Caco-2 cells were cultured in Dulbecco's modified Eagle's medium (DMEM) supplemented with $1 \%$ non-essential amino acids, $1 \%$ Gluta MAX-1, 1\% antibioticantimycotic, $10 \%$ fetal bovine serum at $37^{\circ} \mathrm{C}$, under a $5 \%$ $\mathrm{CO}_{2}$ atmosphere. The cells were seeded on a polycarbonate membrane (Transwell, 12 well, Corning, Corning, NY, U.S.A.) at $1.0 \times 10^{5} \mathrm{cells} / \mathrm{cm}^{2}$, and used for experiments $21-28 \mathrm{~d}$ after seeding.

Synthesis of PEGylated-Poly-L-ornithine PEGylatedpoly-L-ornithine (PEG-PLO) was synthesized as shown in Fig. 1. PLO $(37 \mathrm{mg})$ was dissolved in $0.1 \mathrm{M}$ MES buffer $(\mathrm{pH} 7.0$, $20 \mathrm{~mL}$ ), and then mPEG-NHS $(402 \mathrm{mg}$ ) was dissolved in the PLO solution $(20 \mathrm{~mL})$. The mixture was stirred overnight at room temperature to conjugate $\mathrm{mPEG}$ to PLO. Size-exclusion chromatography consisting of a PROTEIN KW-803 column
(Shodex) and RI-101 refractive index detector (Shodex) was used to confirm that the reaction had finished. A $0.5 \mathrm{~m}$ sodium acetate-acetic acid buffer ( $\mathrm{pH}$ 4.7) was used as the eluent. To elute the cationic compound from the reaction mixture, an ion exchange spin column (Strong Cation Exchange Spin Column Maxi, Thermo Fisher Scientific) was used according to the manufacturer's protocol. The reaction solution $(18 \mathrm{~mL})$ was added to the membrane and centrifuged at $500 \times \boldsymbol{g}$ for $30 \mathrm{~min}$. Purification buffer $(10 \mathrm{~mL}, 25 \mathrm{~mm}$ sodium acetate buffer, $\mathrm{pH}$ 5.5) was added and centrifuged at $500 \times \boldsymbol{g}$ for $10 \mathrm{~min}$. This procedure was repeated twice. Elution buffer $(5 \mathrm{~mL}, 25 \mathrm{~mm}$ sodium acetate buffer containing $1.0 \mathrm{M} \mathrm{NaCl}, \mathrm{pH} 5.5$ ) was added and centrifuged at $500 \times \boldsymbol{g}$ for $5 \mathrm{~min}$. This procedure was repeated twice. The elution solution was dialyzed (Spectra/Por $7, \mathrm{RC}, \mathrm{MWCO}=8 \mathrm{kDa})$ against distilled water $(1 \mathrm{~L})$ for $24 \mathrm{~h}$ (four changes of the outer distilled water). The dialysate was freeze-dried to obtain powdered PEG-PLO.

Characterization of PEGylation Ratio of PEG-PLO Complex Elemental analysis and a TNBS assay were used to determine the PEGylation ratio of PEG-PLO. Elemental analysis was carried out according to a reported method. ${ }^{19)}$ PLO and mPEG-SH were dissolved in distilled water and mixed completely at each ratio, and then these mixtures were freeze-dried. The dried samples were measured with a micro element analyzer (MT-6 CHN Corder, Yanaco, Tokyo, Japan). The carbon-to-nitrogen $(\mathrm{C} / \mathrm{N})$ ratios were calculated for known samples, and a standard curve was plotted. The $\mathrm{C} / \mathrm{N}$ ratio in PEG-PLO was measured in the same manner, and the PEGylation ratio of PEG-PLO was determined from the standard curve. The TNBS assay was performed as previously reported with slight modifications. ${ }^{20)}$ Fifty micrograms per milliliter PEG-PLO $(1 \mathrm{~mL})$ solution and $0.1 \mathrm{M}$ TNBS solution $(75 \mu \mathrm{L})$ were added to $0.1 \mathrm{M}$ sodium tetraborate solution $(2 \mathrm{~mL})$. The mixture was incubated at $37^{\circ} \mathrm{C}$ for $60 \mathrm{~min}$. After incubation, the absorbance at a wavelength of $420 \mathrm{~nm}$ was determined by using a UV-Vis spectrophotometer (UVmini 1240, Shimadzu, Kyoto, Japan). A standard curve of the PEGPLO/PLO absorbance ratio were calculated from the theoretical values of the remaining free primary amine groups. The PEGylation ratio was obtained by reading off the value corresponding to the experimental absorbance ratio from the standard curve. 
(a)

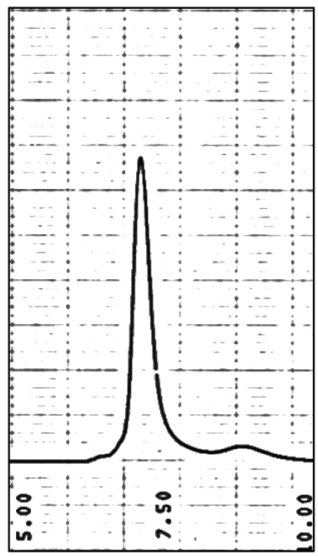

(b)

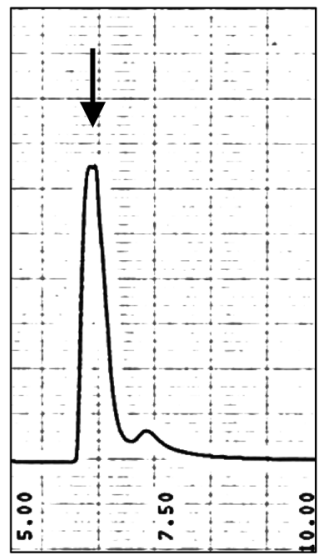

(c)

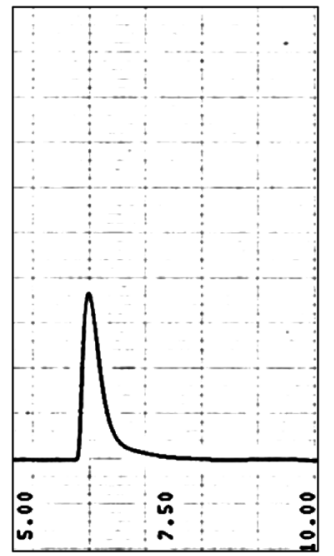

Fig. 2. Typical Chromatograms of Size Exclusion HPLC

(a) Before the reaction of PLO and mPEG-NHS. Peaks were observed at 7.2 and $9.0 \mathrm{~min}$. (b) After the reaction of PLO and mPEG-NHS. Peaks were observed at 6.3 (arrow) and $7.3 \mathrm{~min}$. (c) After extracting the cation compound on a spin column. Only one peak was observed at $6.3 \mathrm{~min}$.

Evaluation of in Vitro Retentivity of PEG-PLO The retentivity of PEG-PLO was evaluated by the inclined plate test as previously reported with modifications. ${ }^{21)}$ A stainless steel plate (SSP) was washed with methanol and dried for $5 \mathrm{~min}$, the plate was inclined at $45^{\circ}$. A $0.1 \%(\mathrm{w} / \mathrm{v})$ PLO or PEG-PLO solution $(35 \mu \mathrm{L})$ was dropped on the plate, and the time it took to travel $4 \mathrm{~cm}$ was measured.

Determination of Membrane Conductance The transepithelial electrical resistance (TEER) was measured using a voltohmmeter (Millicell ERS-2, Merck, Darmstadt, Germany) and was converted to units of ohm square centimeter by multiplying the resistance by the surface area of the membrane. Caco-2 cell sheets were washed with Hank's balanced salt solution (HBSS), and DMEM culture medium was replaced with HBSS. The polycation solutions (PLO and PEG-PLO at various concentrations) were applied to the apical side of the cell sheets. The TEER values were measured at predetermined times after the polycation was applied to the Caco-2 cell sheet. TEER was converted to the membrane conductance $\left(G_{\mathrm{t}}=1 /\right.$ TEER, $\mathrm{mS} / \mathrm{cm}^{2}$ ), and the ratio of $G_{\mathrm{t} 120 \mathrm{~min} / 0 \mathrm{~min}}$ in the treatment group to that in the control group $\left(G_{\mathrm{t}}\right.$ ratio) was calculated.

FD-4 Permeation Experiment The FD-4 permeation experiment was performed as reported previously. ${ }^{22)}$ Caco-2 cell sheets were washed with HBSS, and the DMEM culture medium was replaced with HBSS. The test solutions containing polycations (PLO and PEG-PLO at various concentrations) and FD-4 $(1.0 \mathrm{mg} / \mathrm{mL})$ were applied to the apical side of the cell sheet. Samples were collected from the basolateral side at predetermined times up to $120 \mathrm{~min}$. The cumulative amount of FD-4 that crossed the cell sheet per unit surface area $\left(\mu \mathrm{g} / \mathrm{cm}^{2}\right)$ was calculated. The fluorescence was determined with a spectrofluorophotometer (RF-5300PC, Shimadzu) with an excitation wavelength of $495 \mathrm{~nm}$ and an emission wavelength of $515 \mathrm{~nm}$. The apparent permeability coefficient $(\mathrm{cm} / \mathrm{s}$, $\left.P_{\text {app }}\right)$ of FD-4 was calculated using $P_{\text {app }}(\mathrm{cm} / \mathrm{s})=\mathrm{d} Q / \mathrm{dt} /\left(A \times C_{0}\right)$, where $\mathrm{d} Q / \mathrm{dt}$ is the steady-state permeation rate $(\mu \mathrm{g} / \mathrm{s}), A$ is the surface area of the Transwell membrane $\left(\mathrm{cm}^{2}\right)$, and $C_{0}$ is the initial concentration of FD-4 on the apical side $(\mu \mathrm{g} / \mathrm{mL})$.

Cytotoxicity The MTT assay was performed as previously reported. ${ }^{6,23)}$ In brief, PLO or PEG-PLO solutions were applied to the apical side of Caco-2 cell sheets at various concentrations for $120 \mathrm{~min}$. The solution was replaced with DMEM containing MTT $(0.5 \mathrm{mg} / \mathrm{mL})$. After incubation at $37^{\circ} \mathrm{C}$ for $180 \mathrm{~min}$, the formazan product was released by lysing the cells with dimethyl sulfoxide (DMSO). The absorbance at $540 \mathrm{~nm}$ was measured with a microplate reader (Multiskan Ascent, MTX Lab Systems, Bradenton, FL, U.S.A.). The cell viability was expressed as a percentage of the control.

Statistical Analysis The results are presented as the mean \pm standard errors (S.E.). The two groups were compared using Student's $t$-test. A $p$ value of less than 0.05 was regarded as significant.

\section{RESULTS}

Synthesis of PEG-PLO Complex The side chain PEGylated-PLO was obtained from the amine NHS-ester reaction (Fig. 1), and the product was confirmed by size exclusion HPLC. Peaks derived from PLO and MPEG were observed at 9.0 and $7.2 \mathrm{~min}$, respectively, before the reaction (Fig. 2a). After the reaction, a new peak at $6.3 \mathrm{~min}$ appeared, suggesting conjugation of PEG to PLO (arrow, Fig. 2b). The PLO peak was not observed, indicating that there was no unreacted PLO in the reaction solution. Therefore, the cation exchange spin column extracted only PEG-PLO (Fig. 2c).

Characterization of PEGylation Ratio of PEG-PLO Complex The elemental analysis and TNBS assay were used to determine the PEGylated ratio of PEG-PLO. The elemental analysis showed that the $\mathrm{C} / \mathrm{N}$ ratio and correcting value of PEG-PLO were 38.76 and 33.62, respectively, and that the PEGylation ratio of PEG-PLO was 3.83 (Table 1, Fig. 3a). The TNBS assay showed that absorbance ratio of PEG-PLO/PLO was 0.1234 and that the PEGylation ratio of PEG-PLO was 3.22 (Fig. 3b). Because the values obtained by the elemental analysis and TNBS assay were similar, it was concluded that PEG-PLO bears an average of 3-4 PEG chains per PLO molecule.

In Vitro Retentivity of PEG-PLO The inclined plate test was used to evaluate the retentivity of PEG-PLO (Fig. 4). A $0.1 \%(w / v)$ PLO solution took $6.88 \mathrm{~s}$ to flow down the SSP, similar to water (7.23 s). However, 0.1\% (w/v) PEG-PLO solution took $15.86 \mathrm{~s}$. These results suggested that the adhe- 
Table 1. The Measurement Values and C/N Ratio of PEG-PLO by the Elemental Analysis

\begin{tabular}{|c|c|c|c|c|c|c|c|}
\hline & \multicolumn{3}{|c|}{ Measurements (\%) } & \multirow{2}{*}{$\mathrm{C} / \mathrm{N}$ (Measurement) } & \multirow{2}{*}{$\mathrm{C} / \mathrm{N}$ (Theoretical) } & \multirow{2}{*}{ Measurement/Theoretical } & \multirow{2}{*}{ Measurement deviatior } \\
\hline & $\mathrm{C}$ & $\mathrm{H}$ & $\mathrm{N}$ & & & & \\
\hline $\mathrm{PLO}+\mathrm{PEG}=1: 3$ & 50.52 & 8.62 & 1.65 & 30.62 & 26.42 & 1.16 & 1.15 \\
\hline $\mathrm{PLO}+\mathrm{PEG}=1: 4$ & 51.12 & 8.74 & 1.30 & 39.32 & 34.52 & 1.14 & \\
\hline \multirow[t]{3}{*}{$\mathrm{PLO}+\mathrm{PEG}=1: 5$} & 51.43 & 8.79 & 1.04 & 49.45 & 42.61 & 1.16 & \\
\hline & \multicolumn{3}{|c|}{ Measurements (\%) } & & & & \\
\hline & $\mathrm{C}$ & $\mathrm{H}$ & $\mathrm{N}$ & $\mathrm{C} / \mathrm{N}$ from measurement & Correcting value & PEG/PLO ratio & \\
\hline PEG-PLO & 51.94 & 8.67 & 1.34 & 38.76 & 33.62 & 3.83 & \\
\hline
\end{tabular}

(a)

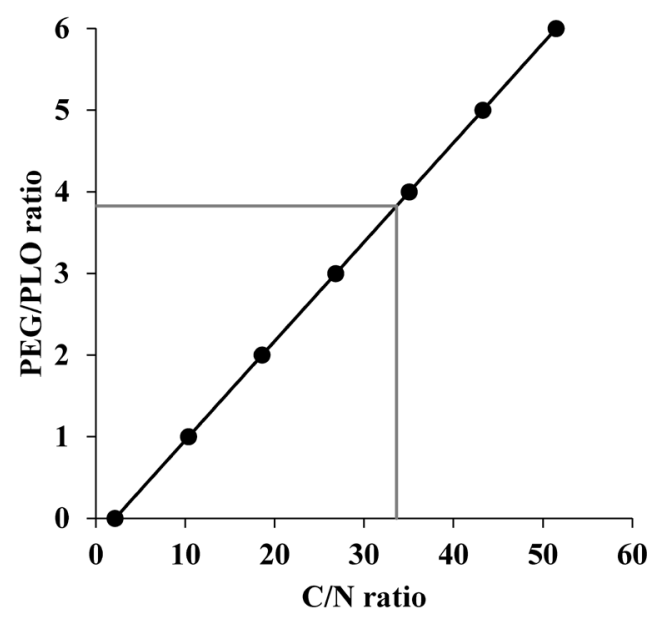

(b)

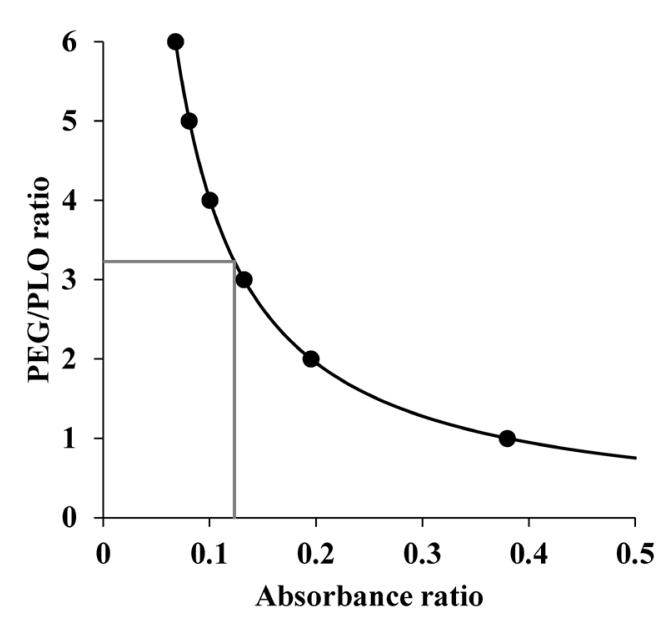

Fig. 3. Determination of PEGylated Ratio of PEG-PLO

(a) Elemental analysis results. Black circles are the $\mathrm{C} / \mathrm{N}$ ratios obtained from each known sample. (b) TNBS assay results. Black circles are the theoretical absorbance ratios of PEG-PLO/PLO.

sion/retention properties of polycations could be improved by PEGylation.

Membrane Conductance and FD-4 Permeation To determine the effects of PLO and PEG-PLO on membrane conductance $\left(G_{t}\right)$ and permeability of macromolecules across the Caco-2 cell sheets, an FD-4 permeation study and TEER measurements were performed after exposure to these polycations. Each $G_{\mathrm{t}}$ was expressed in the ratio of 120 to $0 \mathrm{~min}$ values because the effects of polycations were reached a steady state (Fig. 5A). $G_{\mathrm{t}}$ and $P_{\text {app }}$ of FD-4 in Caco-2 cell sheets were increased dose-dependently by exposure to PEG-PLO and to PLO (Fig. 5B). However, the permeation profiles and cumulative absorption of FD-4 after application of PLO $1 \mu \mathrm{M}$ and PEG-PLO $20 \mu \mathrm{M}$ were almost same (Fig. 5A).

Cytotoxicity Cytotoxicities of PLO and PEG-PLO in Caco-2 cells were determined by an MTT assay (Fig. 6). PLO produced a decrease in cell viability at $1 \mu \mathrm{M}$, a concentration that enhances adsorption. Furthermore, the viability was decreased significantly at the higher concentration $(3 \mu \mathrm{M})$. In contrast, PEG-PLO had no effect on the cell viability even at the highest concentration in this study. The physical mixture of PLO and mPEG-NH $\mathrm{N}_{2}$ containing equimolecular amounts of the PEG-PLO group decreased cell viability at $1 \mu \mathrm{M}$. These results suggest that the cytotoxicity of PLO was decreased by PEGylation.

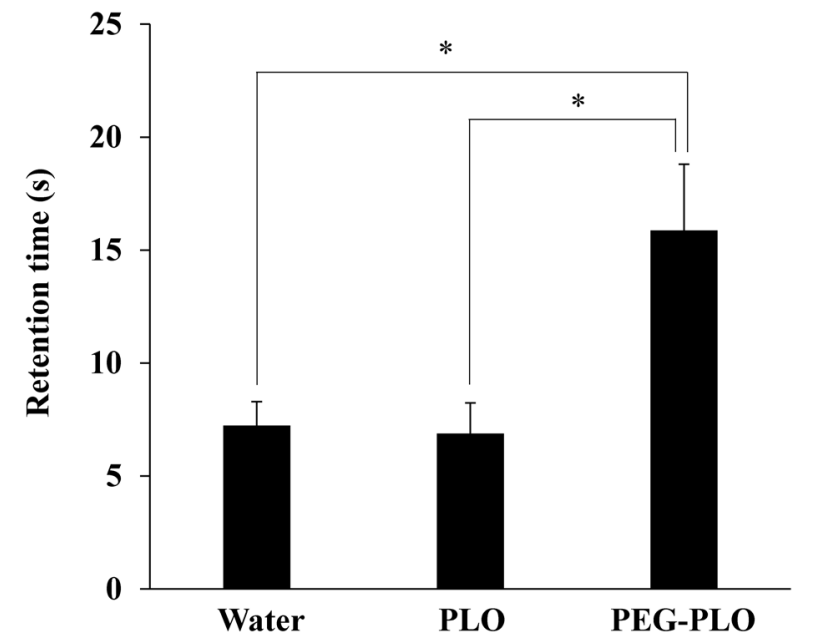

Fig. 4. Retention Time of the PEG-PLO Solution on the Inclined SSP

Retention time was defined as the time required for the solution to flow $4 \mathrm{~cm}$. All measurements were performed at r.t. on the same day. Each data column represents the mean \pm S.E. $(n=6), * p<0.05$.

\section{DISCUSSION}

PLO was PEGylated by an amine-NHS coupling reaction. We had attempted to preparation of PEG-PLA, but it was hard to introduce PEG to PLA. We had confirmed that the permeation stimulatory effect of PLO was higher than PLA 


\section{(A)}

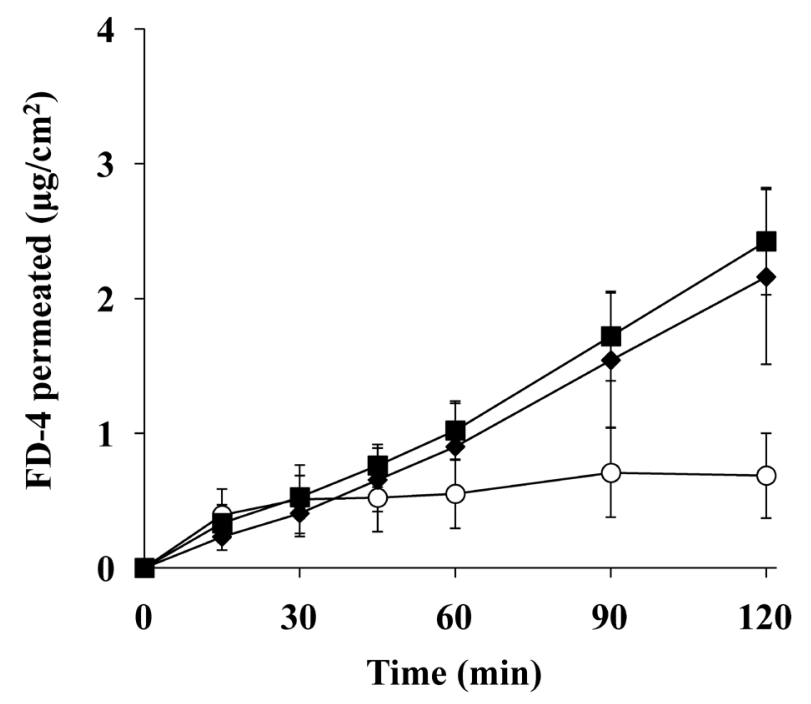

(B)
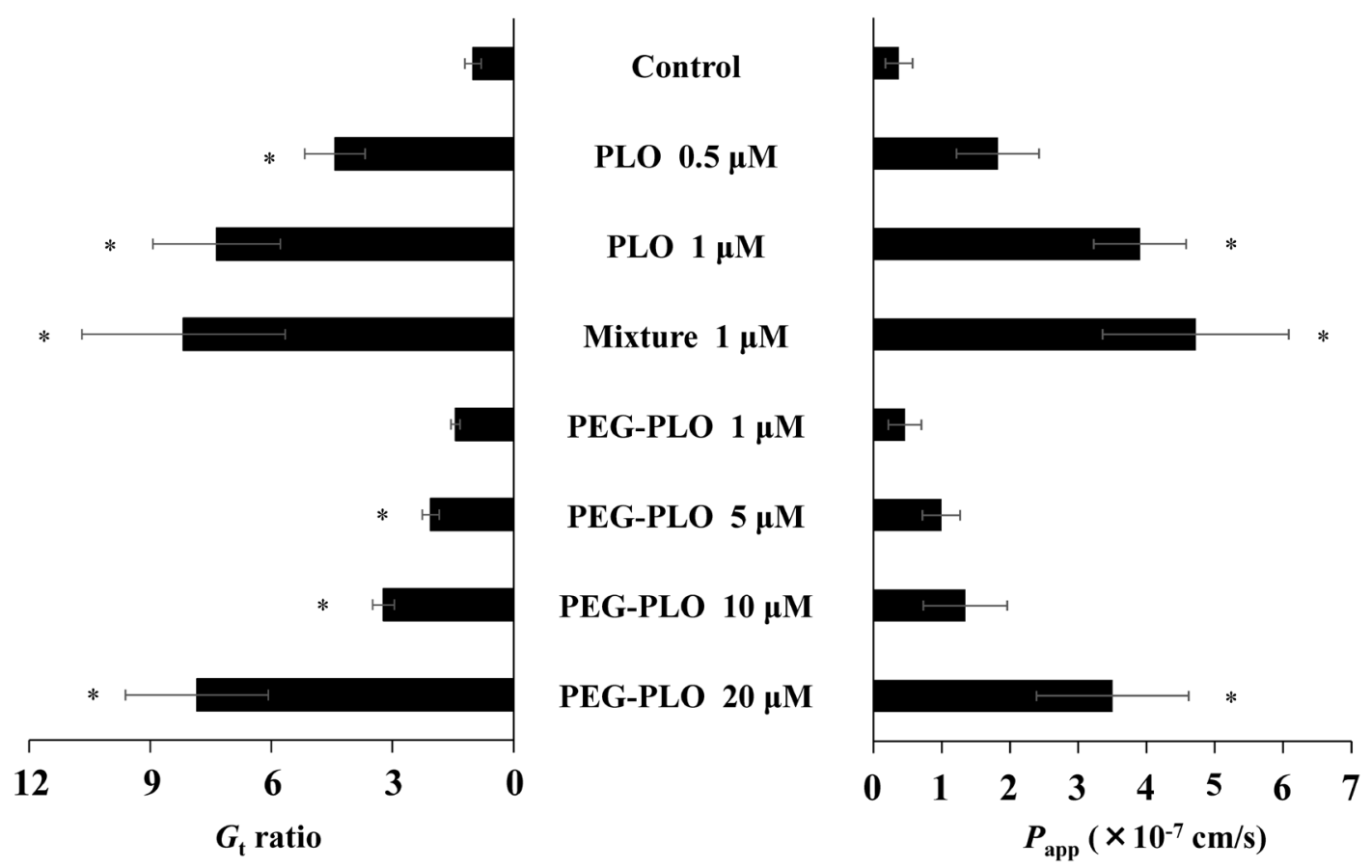

Fig. 5. Effects of Polycations on FD-4 Permeation $\left(P_{\text {app }}\right)$ and Membrane Conductance $\left(G_{t}\right)$ in Caco-2 Cell Sheets

Permeation profiles of FD-4 after application of PLO and PEG-PLO (A). $\bigcirc$ : Control, $\mathbf{\square}$ : PLO $1 \mu \mathrm{M}, \diamond:$ PEG-PLO $20 \mu \mathrm{M}$. The relationships of $P_{\text {app }}$ and $G_{\mathrm{t}}$ after application of PLO and PEG-PLO (B). Control group was treated with vehicle (HBSS). Mixture was a physical mixture of $1 \mu \mathrm{M}$ PLO and $4 \mu \mathrm{M}$ mPEG-NH${ }_{2}$. Each data column represents the mean \pm S.E. $(n=3)$. $* p<0.05 v$ s. control.

and PEGylation of PLO was relatively easy because of its primary amine on the side chain in preliminary study. Therefore, this paper has been described with a focus on the PEG-PLO. Furthermore, we had measured the viscosities of $40 \mathrm{kDa}$ PEG and $10 \mathrm{kDa}$ PEG in preliminary study, the viscosity tended to be increased with the increase in molecular weight of them. We inferred that the viscosity of PEG would become too high if the molecular weight was greater than $40 \mathrm{kDa}$, therefore, we used the $40 \mathrm{kDa}$ PEG in this study. To simplify the purification, PLO was completely reacted by adding excess PEG. In our preliminary study, no unreacted PLO was observed when 5 eq of PEG were used. Hence, PEG-PLO could be purified by only cation extraction. The ion exchange spin column exhibited high selectivity for cationic compounds (Fig. 2). Although the column is suitable for small-scale studies, the purification method would need to be optimized for a large-scale experiment.

Elemental analysis and a TNBS assay were used to evaluate the PEGylation ratio of the PEG-PLO complex. Ideally, the PEGylated site and the number of PEG chains in the polymer are determined. However, modification of a specific site is impossible when using mPEG-NHS in the reaction. Moreover, the degree of polymerization of PLO is not controlled precisely. Therefore, the number of primary amine groups and 


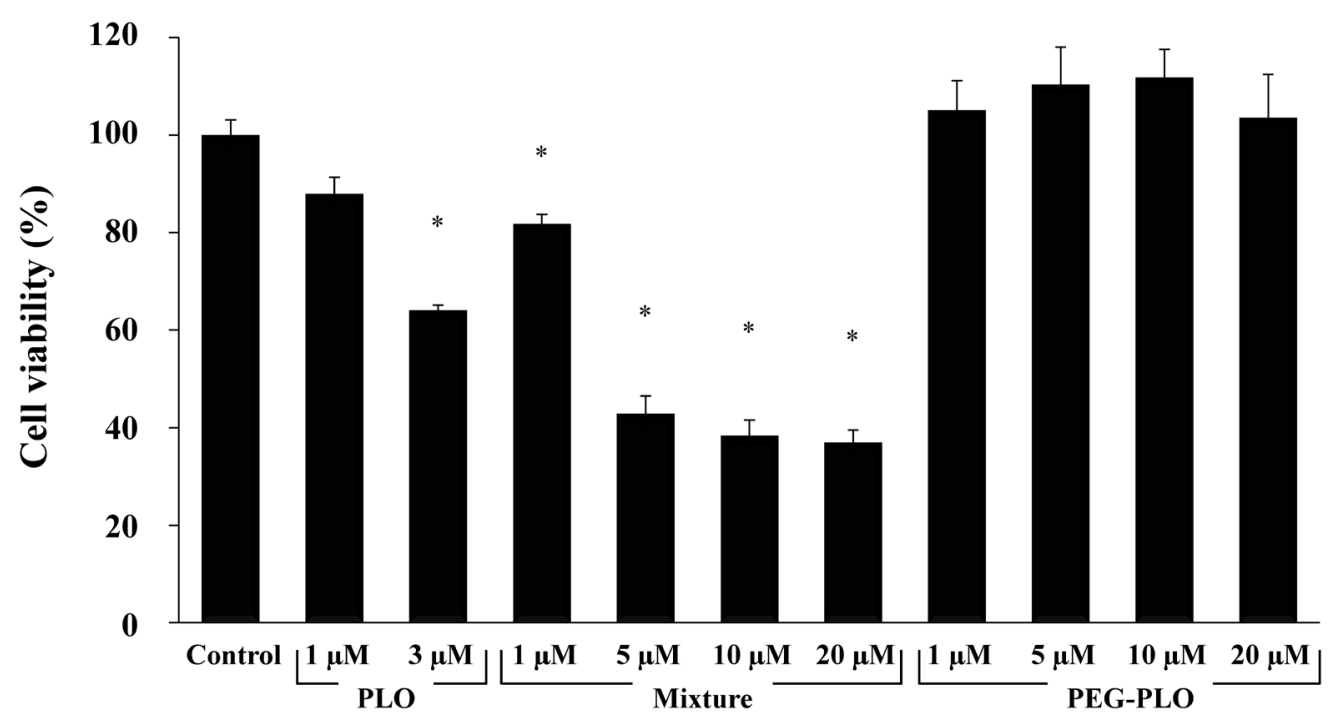

Fig. 6. Effects of Polycations on Cell Viability in Caco-2 Cell Sheets

Control group was treated with vehicle (HBSS). Mixtures: $1 \mu \mathrm{m}: 1 \mu \mathrm{M}$ PLO $+4 \mu \mathrm{M}$ mPEG-NH $2 ; 5 \mu \mathrm{M}: 5 \mu \mathrm{M}$ PLO $+20 \mu \mathrm{m}$ mPEG-NH $2 ; 10 \mu \mathrm{M}: 10 \mu \mathrm{M}$ PLO+40 $\mu \mathrm{M}$ mPEG$\mathrm{NH}_{2} ; 20 \mu \mathrm{m}: 20 \mu \mathrm{M}$ PLO $+80 \mu \mathrm{m}$ mPEG-NH . Each data column represents the mean \pm S.E. $(n=3) .{ }^{*} p<0.05 v s$. control.

the elemental composition were calculated from the degree of polymerization according to the manufacturer's datasheet. The average PEGylated ratio per PEG-PLO molecule was determined by the change in these parameters after PEGylation.

Polycationic absorption enhancers, such as PLA and PLO, do not have mucoadhesive/retentive properties. The retention time of PEG-PLO on an SSP was significantly improved compared with that of PLO $(p<0.05)$, suggesting that PEGylation can increase or impart mucoadhesive/retentive properties. However, the difference between the SSP and real mucosa must be considered. In vivo studies are required to investigate mucoadhesive/retentive properties.

Although PEG-PLO enhanced the permeation of FD-4, the effect was smaller than that of PLO because the steric hindrance of the PEG chain likely affects permeation. The permeation enhancement effect of polycations arises from the interaction between their positive charge and the cell membrane. The molecular weight of PEG used in this study was about $40 \mathrm{kDa}$, and its large chain may have inhibited contact between polycations and the membrane. This attenuation was caused by conjugation of PEG to PLO, but not by the presence of PEG, because there was little difference in the $G_{\mathrm{t}}$ ratio and $P_{\text {app }}$ of FD-4 between PLO and the physical mixture of mPEG-NH $\mathrm{H}_{2}$ and PLO.

The cell viability was $100 \%$ in PEG-PLO at a concentration that showed a sufficient enhancement effect. Previous reports have shown that PLA reversibly enhances the absorption of hydrophilic macromolecules across the epithelium without causing epithelial damage. ${ }^{7)}$ PLO decreased cell viability at a concentration that showed a notable enhancement effect, although the difference was not significant. The cytotoxicity of cationic compounds is caused by the electrostatic interactions with the negative charges on the cell surface. The cell viability was decreased in the physical mixture of PLO and mPEG-NH ${ }_{2}$, suggesting that the cytotoxicity was reduced by the conjugated PEG chains shielding the positively charged amine groups of PLO.

\section{CONCLUSION}

We investigated the effects of chemical modification with PEG on the permeation enhancement effect of PLO. The mucoadhesive/retentive properties of PEG-PLO were improved compared with those of PLO in vitro. PEGylation attenuated the permeation enhancement effect and decreased the cytotoxicity of PLO. These findings provide important information for the development of polycationic absorption enhancers with greater utility.

Conflict of Interest The authors declare no conflict of interest.

\section{REFERENCES}

1) Hosoya $\mathrm{K}$, Kubo $\mathrm{H}$, Natsume $\mathrm{H}$, Sugibayashi $\mathrm{K}$, Morimoto $\mathrm{Y}$. Evaluation of enhancers to increase nasal absorption using Ussing chamber technique. Biol. Pharm. Bull., 17, 316-322 (1994).

2) Hosoya K, Kubo H, Natsume H, Sugibayashi K, Morimoto $Y$, Yamashita S. The structural barrier of absorptive mucosae: site difference of the permeability of fluorescein isothiocyanate-labelled dextran in rabbits. Biopharm. Drug Dispos., 14, 685-695 (1993).

3) McMartin C, Hutchinson LE, Hyde R, Peters GE. Analysis of structural requirements for the absorption of drugs and macromolecules from the nasal cavity. J. Pharm. Sci., 76, 535-540 (1987).

4) Natsume H, Iwata S, Ohtake K, Miyamoto M, Yamaguchi M, Hosoya K, Kobayashi D, Sugibayashi K, Morimoto Y. Screening of cationic compounds as an absorption enhancer for nasal drug delivery. Int. J. Pharm., 185, 1-12 (1999).

5) Ohtake $\mathrm{K}$, Maeno $\mathrm{T}$, Ueda $\mathrm{H}$, Natsume $\mathrm{H}$, Morimoto $\mathrm{Y}$. Poly-Larginine predominantly increases the paracellular permeability of hydrophilic macromolecules across rabbit nasal epithelium in vitro. Pharm. Res., 20, 153-160 (2003).

6) Yamaki T, Ohtake K, Ichikawa K, Uchida M, Uchida H, Ohshima S, Juni K, Kobayashi J, Morimoto Y, Natsume H. Poly-L-arginineinduced internalization of tight junction proteins increases the paracellular permeability of the Caco-2 cell monolayer to hydrophilic macromolecules. Biol. Pharm. Bull., 36, 432-441 (2013).

7) Ohtake K, Natsume H, Ueda H, Morimoto Y. Analysis of transient and reversible effects of poly-L-arginine on the in vivo nasal ab- 
sorption of FITC-dextran in rats. J. Control. Release, 82, 263-275 (2002).

8) Miyamoto M, Natsume H, Satoh I, Ohtake K, Yamaguchi M, Kobayashi D, Sugibayashi K, Morimoto Y. Effect of poly-L-arginine on the nasal absorption of FITC-dextran of different molecular weights and recombinant human granulocyte colony-stimulating factor (rhG-CSF) in rats. Int. J. Pharm., 226, 127-138 (2001).

9) Ohtake $\mathrm{K}$, Maeno $\mathrm{T}$, Ueda $\mathrm{H}$, Ogihara M, Natsume H, Morimoto Y. Poly-L-arginine enhances paracellular permeability via serine/ threonine phosphorylation of ZO-1 and tyrosine dephosphorylation of occludin in rabbit nasal epithelium. Pharm. Res., 20, 1838-1845 (2003).

10) Soane RJ, Frier M, Perkins AC, Jones NS, Davis SS, Illum L. Evaluation of the clearance characteristics of bioadhesive systems in humans. Int. J. Pharm., 178, 55-65 (1999).

11) Gizurarson S. The effect of cilia and the mucociliary clearance on successful drug delivery. Biol. Pharm. Bull., 38, 497-506 (2015).

12) Irie H, Ohtake K, Maeno T, Uchida M, Uchida H, Kobayashi J, Natsume H. Relationship between calcein disposition in nasal cavity and blood concentration after intranasal administration of viscous calcein-loaded starch solution in rats. J. Pharm. Sci. Technol. Jpn., 69, 219-227 (2009).

13) Ananda $\mathrm{K}$, Manjula $\mathrm{BN}$, Meng $\mathrm{F}$, Acharya VN, Intaglietta $\mathrm{M}$, Acharya SA. Packing density of the PEG-shell in PEG-albumins: PEGylation induced viscosity and COP are inverse correlate of packing density. Artif. Cells Blood Substit. Immobil. Biotechnol., 40, 14-27 (2012).

14) Zeuzem S, Feinman SV, Rasenack J, Heathcote EJ, Lai MY, Gane E, O'Grady J, Reichen J, Diago M, Lin A, Hoffman J, Brunda MJ. Peginterferon alfa-2a in patients with chronic hepatitis C. N. Engl. J. Med., 343, 1666-1672 (2000).

15) Lee KC, Tak KK, Park MO, Lee JT, Woo BH, Yoo SD, Lee HS, DeLuca PP. Preparation and characterization of polyethylene- glycol-modified salmon calcitonins. Pharm. Dev. Technol., 4, 269-275 (1999)

16) Kim TH, Jiang HH, Lim SM, Youn YS, Choi KY, Lee S, Chen X, Byun Y, Lee LC. Site-specific PEGylated Exendin-4 modified with a high molecular weight trimeric PEG reduces steric hindrance and increases type 2 antidiabetic therapeutic effects. Bioconjug. Chem., 23, 2214-2220 (2012).

17) Veronese FM, Mero A. The impact of PEGylation on biological therapies. BioDrugs, 22, 315-329 (2008).

18) Huang Y, Leobandung W, Foss A, Peppas NA. Molecular aspects of muco- and bioadhesion: tethered structures and site-specific surfaces. J. Control. Release, 65, 63-71 (2000).

19) Gol RM, Jewrajka SK. Facile in situ PEGylation of polyamide thin film composite membranes for improving fouling resistance. $J$. Membr. Sci., 455, 271-282 (2014).

20) Brown MD, Schätzlein A, Brownlie A, Jack V, Wang W, Tetley L, Gray AI, Uchegbu IF. Preliminary characterization of novel amino acid based polymeric vesicles as gene and drug delivery agents. Bioconjug. Chem., 11, 880-891 (2000).

21) Castile J, Cheng YH, Simmons B, Perelman M, Smith A, Watts P. Development of in vitro models to demonstrate the ability of PecSys $^{\left({ }^{(}\right)}$, an in situ nasal gelling technology, to reduce nasal run-off and drip. Drug Dev. Ind. Pharm., 39, 816-824 (2013).

22) Yamaki T, Kamiya Y, Ohtake K, Uchida M, Seki T, Ueda H, Kobayashi J, Morimoto Y, Natsume H. A mechanism enhancing macromolecule transport through paracellular spaces induced by Poly-L-arginine: Poly-L-arginine induces the internalization of tight junction proteins via clathrin-mediated endocytosis. Pharm. Res., 31, 2287-2296 (2014)

23) Maher S, McClean S. Investigation of the cytotoxicity of eukaryotic and prokaryotic antimicrobial peptides in intestinal epithelial cells in vitro. Biochem. Pharmacol., 71, 1289-1298 (2006). 